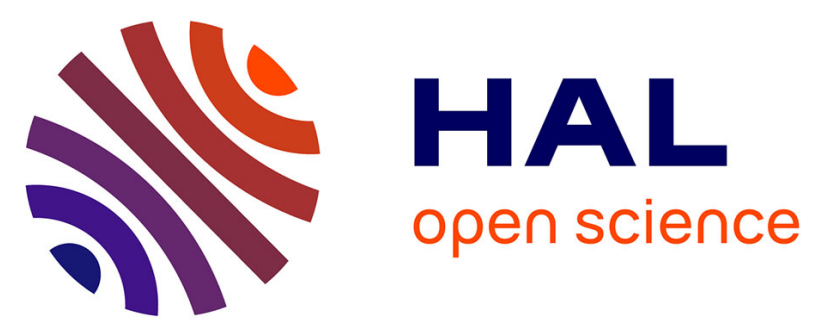

\title{
Impact of Atmosphere on Recovered Carbon Fibers From Poly Ether Ether Ketone (PEEK) Based Composites During Thermoconversion
}

P. Fontaine, Elsa Weiss-Hortala, V. Botaro, J. Paiva, Yannick Soudais

\section{- To cite this version:}

P. Fontaine, Elsa Weiss-Hortala, V. Botaro, J. Paiva, Yannick Soudais. Impact of Atmosphere on Recovered Carbon Fibers From Poly Ether Ether Ketone (PEEK) Based Composites During Thermoconversion. Waste and Biomass Valorization, 2021, 12, pp.6389-6402. 10.1007/s12649-021-01445-7 . hal-03224283

\section{HAL Id: hal-03224283 \\ https://imt-mines-albi.hal.science/hal-03224283}

Submitted on 14 May 2021

HAL is a multi-disciplinary open access archive for the deposit and dissemination of scientific research documents, whether they are published or not. The documents may come from teaching and research institutions in France or abroad, or from public or private research centers.
L'archive ouverte pluridisciplinaire HAL, est destinée au dépôt et à la diffusion de documents scientifiques de niveau recherche, publiés ou non, émanant des établissements d'enseignement et de recherche français ou étrangers, des laboratoires publics ou privés. 


\title{
Impact of Atmosphere on Recovered Carbon Fibers From Poly Ether Ether Ketone (PEEK) Based Composites During Thermoconversion
}

\author{
P. Fontaine ${ }^{1,2,3} \cdot$ E. Weiss-Hortala ${ }^{2}$ - V. Botaro ${ }^{3}$. J. M. F. Paiva ${ }^{3} \cdot$ Y. Soudais $^{2}$
}

\begin{abstract}
Carbon Fibers Reinforced Polymer composites (CFRP) are high added value materials used in many manufactured products. Especially in aeronautics, thermosetting resins tend to be replaced by heat-resistant thermoplastic polymers. The aim of the work is to evaluate suitable operating conditions of thermoconversion for the recovery of carbon fibers from Poly Ether Ether Ketone (PEEK)/carbon fibers composites. Micro and pilot scale tests have been performed in nitrogen, wet nitrogen, air, and wet air. Thermogravimetric analysis of PEEK/carbon fiber composites showed a moderate decomposition onset temperature of the composite at $515^{\circ} \mathrm{C}$ and $510^{\circ} \mathrm{C}$ in dry nitrogen and dry air respectively. The oxidative atmosphere did not significantly impact this temperature since the first mass loss was not atmosphere dependent. However, after the first PEEK degradation reaction, the nature of the atmosphere appeared as a great issue. Total mass loss was significantly improved with temperature (full oxidation of polymer and carbon fibers up to $800^{\circ} \mathrm{C}$ ) and with reaction time using air. Indeed, at pilot scale, the matrix was fully degraded in air atmosphere at $550{ }^{\circ} \mathrm{C}$ for $1 \mathrm{~h}$ while only $42 \%$ and $46 \%$ was reached in nitrogen and steam/nitrogen respectively. Comparison of thermogravimetric data between wet and dry atmospheres revealed that steam plays a thermal retardant role leading to some differences on the matrix degradation and on the surface morphology of the carbon fiber at pilot scale. Air treatments at pilot scale induced a reduction of fiber diameters $(<-3.7 \%)$ but the tensile strengths of recovered carbon fibers were preserved with an average retention of mechanical properties of $81 \%-85 \%$. It has been concluded that recycling of PEEK/carbon composite required an oxidant to split up carbon fibers from the PEEK matrix.
\end{abstract}

P. Fontaine

pauline.fontaine@mines-albi.fr

1 ADEME Agence de la transition écologique, 49000 Angers, France

2 UMR 5302 Mines Albi, RAPSODEE Center CNRS, 81013 ALBI Cedex 9, France

3 Federal University of São Carlos (UFSCar), Campus Sorocaba, São Carlos, Brazil 


\section{Graphic Abstract}

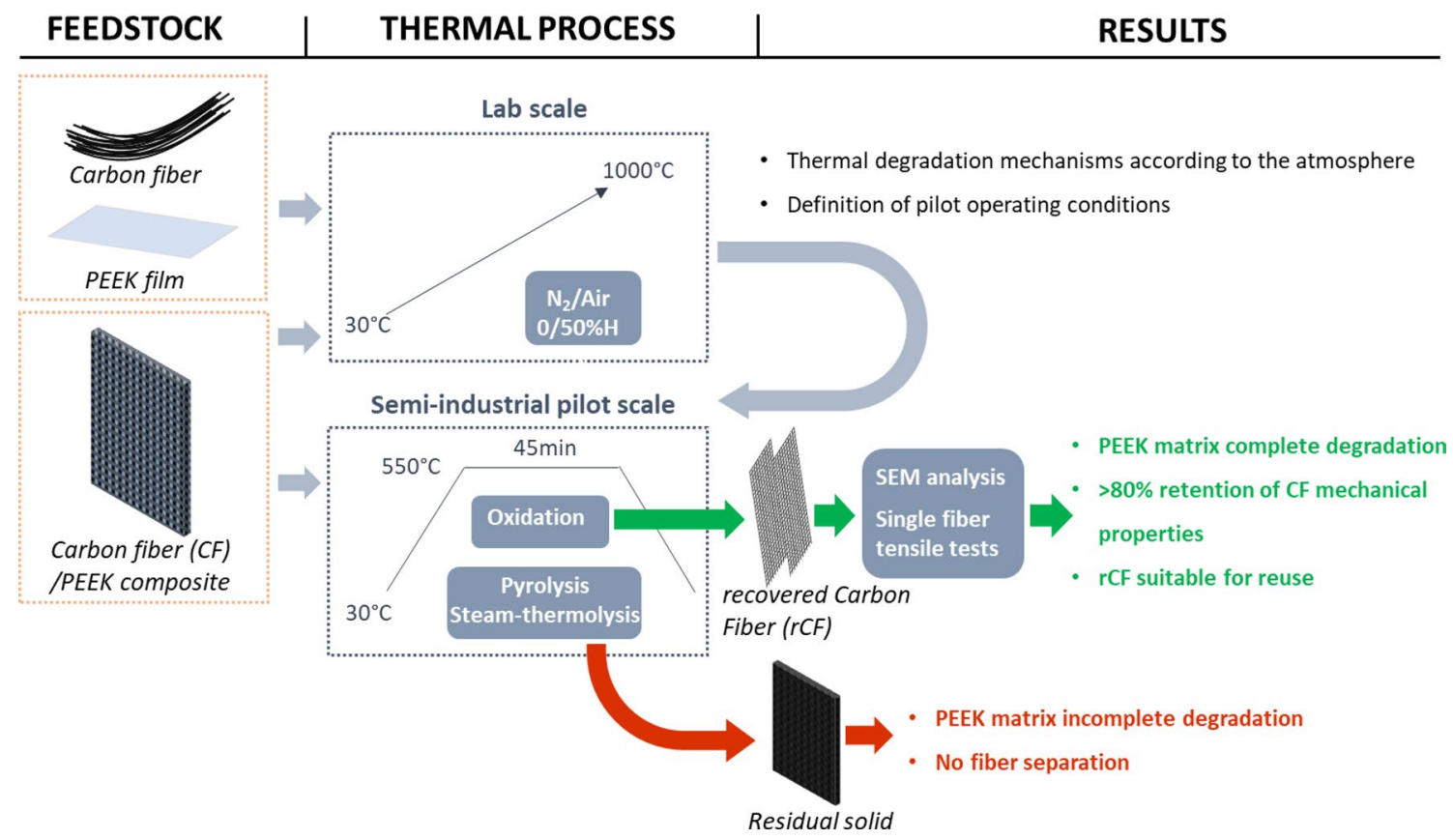

Keywords PEEK/carbon Composites $\cdot$ Thermal degradation $\cdot$ Atmosphere $\cdot$ Recycling

\section{Statement of Novelty}

This paper is focused on carbon fiber/PEEK composites recycling to anticipate their end of life. PEEK is a heatresistant polymer, and its thermal degradation is a great issue for the future management of these composites. Basically, the recovery of carbon fibers requires the separation of carbon fibers from the matrix, using thermal or chemical treatments. The aim of this paper is to investigate the thermal treatment using various atmospheres to reach at least the recovery of carbon fibers, and more specifically to obtain carbon fibers with good mechanical properties for reuse. This is a first study investigating the impact of the atmosphere on the mechanical quality of carbon fibers from thermoxidative recycling process of PEEK composites.

\section{Introduction}

Carbon Fibers Reinforced Polymers (CFRP) are high added value materials used in many manufactured products, from sports to aeronautics. The development of CFRP was due to their lightness and strength, offering many new possibilities to reduce the weight of materials while keeping the strength $[1,2]$. Polymers used in CFRP are usually thermosetting or thermoplastic matrix [3]. Thermosetting matrix, which cannot be melt or easily recycled [4], were likely used due to their easier processability. However, these polymers require low-temperature storage and long curing cycles. To overcome these drawbacks, aeronautics recently turned to the use of thermoplastics, and more specifically heat-resistant thermoplastics to keep high-performance composites [5]. Indeed, these matrices have a better manufacturing efficiency, they improve the flame retardancy of the final product, and their meltability theoretically offers recyclability options [6]. Particularly for aeronautical applications, Poly Ether Ether Ketone (PEEK), PolyetherImide or Polyphenylene Sulphide are used for the production of high-performance composites [7].

Poly Ether Ether Ketone (PEEK, $\left[-\mathrm{O}-\mathrm{C}_{6} \mathrm{H}_{4}-\mathrm{CO}-\mathrm{C}_{6} \mathrm{H}_{4}-\right.$ $\left.\mathrm{O}-\mathrm{C}_{6} \mathrm{H}_{4}-\right]_{\mathrm{n}}$ ) is a heat-resistant thermoplastic polymer with excellent mechanical, chemical and thermal properties. Its long-term temperature resistance mostly comes from the presence of rigid conjugated aromatic rings in the polymer chain, making chemical or thermal attack more difficult. The semi-crystallinity of this material increases also the stiffness and tensile strength and the impact energy absorption [8]. Because of their robustness, carbon fiber reinforced PEEK is increasingly used to replace carbon fiber/thermosetting resins composite. The global demand of this heat resistant 
material is expected to continue growing in the next decade, with an increase in the composite waste volume as a consequence [9, 10].

Replacement of thermosetting by thermoplastic polymer may offer new recyclability options, as the matrix can be melted several times. Nevertheless, a major recycling CFRPs issue is the alignment and the length of carbon fibers in the composite which can limit their reuse [11]. Viable recycled carbon fiber reemployment can be done by injection molding for short fiber lengths. Regarding longer fibers, their fuzzy aspect after recycling necessarily involves an additional pre-manufacturing stage. Thereby, the recovery of fibers from CFRPs raises many questions; from recycling process optimization to economics and ecological aspects $[10,12]$. For now, opportunities to reuse rCFs exist in automotive components where rCFs based composites can be a competitive material that can replace conventional metal or virgin CFRP [13].

Simplest ways carried out for end-of-life composites are grinding or incineration. Due to new European directives, and strategies along EU Waste hierarchy, new options that minimize the environmental impact and reduce the cost of manufacturing should be developed. Until now, recycling of composites was investigated to recover and reuse carbon fibers, which are the petroleum-based added-value materials. Since grinding does not separate fibers from matrix, thermal and chemical treatments were likely investigated. At industrial scale, pyrolysis appears as the most reliable technique [9]. Pyrolysis is a thermal treatment commonly performed at atmospheric pressure in nitrogen atmosphere and at mild temperatures $\left(400-600{ }^{\circ} \mathrm{C}\right)$ which results in three phases. Basically, organics (mostly the matrix) are converted to gaseous and oily phases while the carbon fibers and ashes are recovered in the solid phase. This process was mostly investigated for thermoset polymer-based composites (especially epoxy resins), and after optimization of operating conditions, it produced short and discontinuous fibers with almost suitable mechanical properties [14]. However, pyrolysis shows some drawbacks: optimization of operating conditions is hardened by treating mixtures (various kind of matrices); the surface of recovered carbon fibers may contain polymer and/or pyrolytic residues which impact mechanical properties and reprocessing as well [15]. To improve the quality of recovered carbon fiber surfaces, two options were investigated, oxidation as a post-treatment [16, 17] or steamthermolysis [18] instead of pyrolysis. Oxidation post-treatment is performed with continuous air flow to remove pyrolytic residues. Operating conditions should finely be tuned to prevent modifications of carbon fiber surface like insertion of oxygen atoms and formation of surface defects. Steamthermolysis is a pyrolysis-based process using superheated steam at environmental pressure as a soft oxidant. It was efficient to convert thermoset and thermoplastic polymers from waste composites resulting in recovered carbon fibers with adequate quality for reuse [19, 20]. More importantly, the presence of steam was shown to be efficient for avoiding pyrolytic carbon deposition.

Heat-resistant matrix degradation for carbon fiber recovery is challenging. Indeed, as mentioned previously PEEK has good thermal and chemical resistances, and this matrix is an added-value chemical as well. On the one hand some processes have been studied, based on chemical matrix decomposition or physical fragmentation [21-24]. For example, the successful decomposition of the entire matrix at $350{ }^{\circ} \mathrm{C}$ in only $30 \mathrm{~min}$ have been reached with high pressure bomb reactor containing a co-solvent system (ethanol/water) and cesium carbonate [22]. The carbon fibers were recovered while the polymeric matrix could not be recovered. On the other hand, the thermal recycling treatment of carbon fiber reinforced heat-resistant thermoplastic matrix has not been investigated yet. Thermoconversion is a way to recover both carbon fibers in the solid phase and valuable chemicals in the oily or aqueous phase.

The present work is therefore focused on the recycling of carbon fibers from heat-resistant polymer composites using thermoconversion. The treatment of PEEK composite under four inert and oxidative atmospheres was carried out at micro and at pilot scale. Physical and chemical analysis of the solid phase were performed to evaluate the impact of the operating conditions (temperature and atmosphere) and the quality of the recovered carbon fibers ( $\mathrm{rCF}$ ) in terms of surface morphology and mechanical properties.

\section{Materials and Experimental Procedures}

\section{Feedstock}

Three resources were used for this study: matrix, carbon fiber and the final composite. PEEK matrix, supplied by Victrex (Lancashire, UK), was a thin film of 100 microns, specifically used for thermogravimetric analysis. Carbon fibers FT300® yarn from Toray Carbon Fibers Europe (Lacq, France), referenced in this paper as "virgin fiber", were used as such for thermal and morphological characterizations. According to the supplier these fibers present a tensile strength of $3530 \mathrm{MPa}$ for a diameter of $7.30 \mu \mathrm{m}$. The resulting PEEK/Carbon fibers composite was manufactured at lab scale by ICA laboratory at IMT Mines Albi (Albi, France). The amount of matrix in the composite waste was experimentally checked by a sulfuric acid chemical degradation (according to the NF2564 [25]). The matrix and fibers represented $42 \mathrm{wt} . \%$ and $58 \mathrm{wt} . \%$ respectively. All the composite scraps were cut in rectangles of 5 to $7 \mathrm{~cm}$ length and 2 to $4 \mathrm{~cm}$ width to fit the reactor size. Thermoconversion of the composite was performed at microscopic and pilot scales. 
For tables and figures along the paper, Carbon/PEEK composite, PEEK matrix and FT300 carbon fibers are referred to as CPEEK, PEEK and FT300 respectively.

\section{Thermogravimetric Analysis}

Thermogravimetric analysis of the PEEK polymer, virgin carbon fibers, and PEEK/carbon composite were performed in both nitrogen and air atmospheres. Dynamic thermogravimetry was carried out with an STA 409 PC® (Netzsch, Selb, Deutschland) equipment. The samples were placed in a platinum crucible and heated to $1000{ }^{\circ} \mathrm{C}$ at $5{ }^{\circ} \mathrm{C} / \mathrm{min}$ with a gas flow rate of $100 \mathrm{~mL} / \mathrm{min}$. The TGA heating rate was set to be equivalent as the one applied at pilot scale. Humid gaseous atmospheres (in nitrogen and air) were carried out with Tg-ATD 92® (Setaram, Caluire, France) unit mounted with humidity generator $\left(50 \mathrm{RH} \%\right.$ at $\left.40{ }^{\circ} \mathrm{C}\right)$. These tests were performed following the same heating rate with $50 \mathrm{~mL} /$ min of gas flow rate.

\section{Pilot Plant and Protocol}

Recycling treatment was performed in a semi-industrial pilot plant of $1 \mathrm{~L}$ capacity using $20 \mathrm{~g}$ of composite. Figure 1 shows the scheme of the reactor, which consisted of an alumina crucible placed in a cylindrical oven surrounded by heating coils [18]. The internal chamber was continuously flowed by gas: nitrogen or air. In addition, a

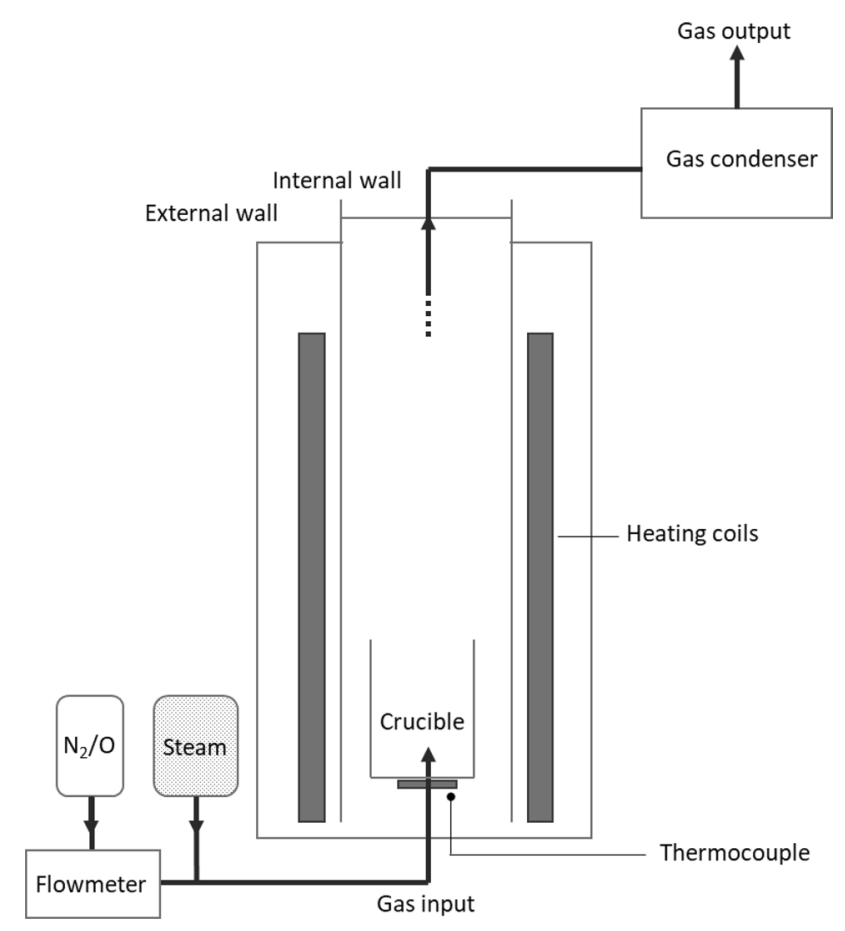

Fig. 1 Scheme of the pilot plant for the thermal treatment at semiindustrial scale steam generator was used to work in humid atmospheres. This configuration allowed to work in various atmospheres either or not with steam $[19,20,26]$. Temperature inside the chamber was measured by a thermocouple located under the crucible support.

The experimental procedure was as follows: around $20 \mathrm{~g}$ of PEEK composite scraps were vertically placed inside the crucible which was then introduced into the reactor. Dry gas flow (air or nitrogen) was introduced at a $5 \mathrm{~L} / \mathrm{min}$ flow rate prior to the heating. The reactor was heated at $5{ }^{\circ} \mathrm{C} / \mathrm{min}$ up to $550{ }^{\circ} \mathrm{C}$ and maintained at isothermal stage for $45 \mathrm{~min}$. These operating conditions were chosen based on a previous study investigating the steam-thermolysis recycling of Polyphenylene Sulphide carbon composites [20]. After isothermal plateau, the reactor was cooled down to atmospheric temperature at a constant rate of $5{ }^{\circ} \mathrm{C} / \mathrm{min}$. For experiments performed with steam, $50 \mathrm{~g} / \mathrm{h}$ of superheated steam $\left(180{ }^{\circ} \mathrm{C}\right)$ was mixed with the gas flow and introduced above $300{ }^{\circ} \mathrm{C}$ while heating. During cooling step, steam was stopped when temperature reached $300{ }^{\circ} \mathrm{C}$. Table 1 describes the operating conditions for each sample. Four inert and oxidative atmospheres were chosen to study the PEEK composite recycling: nitrogen $(\mathrm{N})$, nitrogen and steam (NS), air (A) and air and steam (AS). Each experiment was performed in triplicate.

\section{Characterization of Recovered Solids}

Recovered solids were characterized in terms of matrix degradation rate, morphology and mechanical properties.

\section{- Matrix degradation rate}

Matrix degradation rate, denoted as $y_{m}$, was calculated to evaluate the efficiency of the process under operating conditions. Indeed, high matrix removal should be reached to ensure the separation of the monofilaments $\left(y_{m}>75 \%\right)$ and therefore allowing their reuse [26]. This parameter was calculated according to Eq. (1):

Table 1 Operating conditions applied to the thermal treatment of PEEK composite

\begin{tabular}{llllll}
\hline Sample & $\begin{array}{l}\text { Tem- } \\
\text { perature } \\
\left({ }^{\circ} \mathrm{C}\right)\end{array}$ & $\begin{array}{l}\text { Residence } \\
\text { time }(\mathrm{min})\end{array}$ & Gas nature & $\begin{array}{l}\text { Gas flow } \\
\text { rate }(\mathrm{L} / \\
\mathrm{min})\end{array}$ & $\begin{array}{l}\text { Steam } \\
\text { flow rate } \\
(\mathrm{g} / \mathrm{h})\end{array}$ \\
\hline $\mathrm{C}_{\mathrm{PEEK}}-\mathrm{N}$ & 550 & 45 & Nitrogen & 5 & 0 \\
$\mathrm{C}_{\mathrm{PEEK}}-\mathrm{NS}$ & 550 & 45 & $\begin{array}{l}\text { Nitrogen/ } \\
\text { steam }\end{array}$ & 5 & 50 \\
$\mathrm{C}_{\mathrm{PEEK}}-\mathrm{A}$ & 550 & 45 & Air & 5 & 0 \\
$\mathrm{C}_{\mathrm{PEEK}}-\mathrm{AS}$ & 550 & 45 & Air/steam & 5 & 50 \\
\hline
\end{tabular}


$y_{m}=\frac{\Delta m}{m i_{\text {composite }} \times w_{\text {matrix }}} \times 100$

where $\Delta m=m i_{\text {composite }}-m f_{\text {solid }}$ is the difference between initial and final mass of the solid, and $w_{\text {matrix }}$ is the matrix mass fraction within the composite, determined by chemical degradation previously mentioned in Sect. 2.1. Since this parameter was only based on the matrix removal, a value greater than $100 \%$ indicates the degradation of the carbon fibers.

\section{- Morphological analysis}

Scanning electron microscopy, carried out with aTM3030+ (B (Hitachi, Chiyoda, Japan) device, was used to locally observe the quality of recovered carbon fibers. This technique highlighted the residual matrix and / or a local degradation of the fiber surface. SEM analysis were carried out with an accelerating voltage of $15 \mathrm{kV}$ and magnifications of $\times 1500, \times 2500$ and $\times 4000$. Then, an image treatment of the SEM pictures was performed to record the average diameter of single $\mathrm{rCF}$, since a reduced diameter should evidence fiber degradation. This diameter was also taken into account in the determination of the maximum stress at break. Two fiber sampling areas were defined, as shown in Fig. 2, in order to provide better interpretations by considering internal and external zones.

\section{Single Fiber Tensile Test}

The mechanical properties of carbon fiber after the recycling process were quantified through a single fiber tensile test according to the international standard ISO 11,566. Tensile tests were performed on an Instron (Norwaad, USA) device equipped with two vertical load cells of $5 \mathrm{~N}$ pulling at $1 \mathrm{~mm} /$ $\mathrm{min}$. The rCF sample gauge length was $25 \mathrm{~mm}$. The specimens

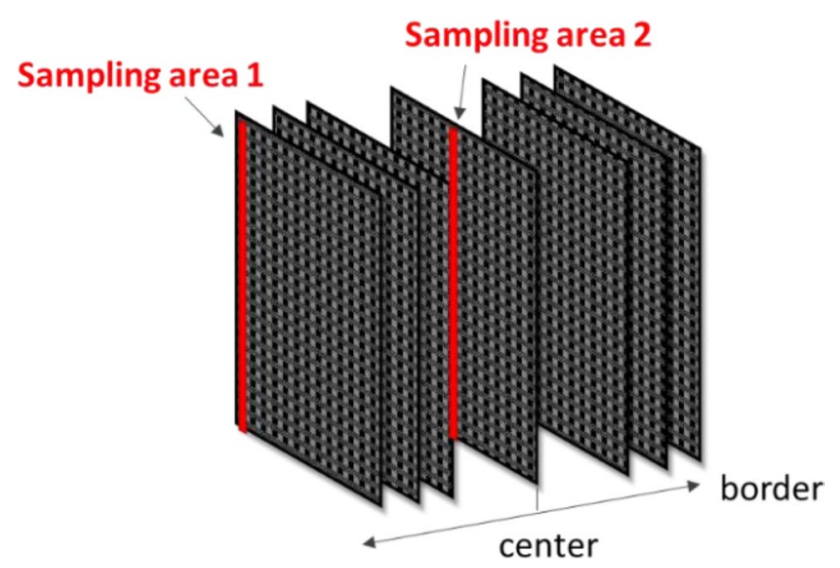

Fig. 2 Representation of rCF sampling areas from composite residue for morphological and mechanical characterizations were loaded until failure. The tensile strength of the rCFs was deduced thanks to the recorded force-displacement curve. To obtain a representative database, at least 20 filaments per zone (defined sampling zones showed in Fig. 2) were tested for each experiment. The rCF filaments which broke during sample installation were taken into account in the further statistical analysis. The retention of the carbon fiber tensile strength after recycling was then calculated according to Eq. (2):

$R=\frac{\sigma_{\text {test }}}{\sigma_{\text {reference }}} \times 100$

where $\sigma_{\text {reference }}$ is the virgin fiber tensile strength (according to supplier data) and $\sigma_{\text {test }}$ is the tensile strength of recovered carbon fibers. The closer $\mathrm{R}$ was to $100 \%$, the less the recovered fibers were impacted by the treatment.

Due to fragile failure mode of carbon fiber, the expected standard deviations are broad [27] and the measured experimental strength cannot be captured in one single average value. Since the occurrence of flaws exhibited a random nature, single filament test data may be completed by a statistical model. The most widely used statistical function to assess the strength of brittle fibers, such as carbon, is the Weibull distribution [28]. The common 2-parameters Weibull distribution function for fiber strengths, assuming a uniform stress along the fiber and a fixed gauge length, is given by Eq. (3) [29].

$P(\sigma)=1-\exp \left\{-\left(\frac{\sigma}{\sigma_{0}}\right)^{m}\right\}$

where $P(\sigma)$ is probability of fiber failure, $\sigma$ the fiber strength $(\mathrm{MPa}), \sigma_{0}$ the scale parameter $(\mathrm{MPa}), m$ the Weibull modulus.

The scale parameter reflects the stress level for which the fracture probability of $63 \%$ and the Weibull modulus characterizes the dispersion of flaws for a given material [30]. The larger the latter, the lower the disparity of flaw and therefore of the activation tensile stress. The rearrangement of the Weibull cumulative expression gives the Eq. 4 .

$\ln \left(\ln \frac{1}{1-P}\right)=m \ln \sigma-m \ln \sigma_{0}$

Assuming that the material obeys a Weibull law, $\mathrm{m}$ and $\sigma_{0}$ can be obtained from the linear fitting of $\ln (-\ln (1-P))$ and $\ln$ $\sigma$. Weibull distribution have been calculated for 20 samples of virgin FT300 resulting in a Weibull modulus of 8.28 and a scale parameter of $3012 \mathrm{MPa}$.

\section{Results and Discussion}

Focus have been made through this study on the recycling possibility of PEEK composite and on the quality of the recovered carbon fiber. Preliminary thermal studies were 
performed with thermogravimetric analysis in dynamic mode to identify degradation range and mechanisms. After pilot treatment, the recovered solid was analyzed and the carbon fibers were extracted when possible. These carbon fibers were characterized via morphological and mechanical analysis to evaluate the surface characteristics and the retention of the tensile properties.

\section{Thermal Behavior of PEEK Composite and its Components at Micro Scale}

This section details the thermal behavior of PEEK composite, matrix, and virgin fibers in various atmospheres: dry and wet nitrogen, dry and wet air, from $30{ }^{\circ} \mathrm{C}$ to $1000{ }^{\circ} \mathrm{C}$ at $5{ }^{\circ} \mathrm{C} /$ min using TGA. For wet atmospheres, relative humidity was equal to $50 \%$ at $40{ }^{\circ} \mathrm{C}$. Two characteristic temperatures were extracted from the TGA curves: the decomposition onset temperature and the temperature relative to the mass loss stabilization. In addition, the total mass loss was recorded, and these three data are displayed in Table 2. The thermal behaviors of the samples under dry and wet nitrogen and under dry and humid air are illustrated in Fig. 3 and Fig. 4 respectively.

PEEK composite and its individual components were first analyzed under nitrogen atmosphere. The TG curves (Fig. 3a) show that the PEEK polymer, whether tested alone or present in the composite, starts to decompose at $515{ }^{\circ} \mathrm{C}$ under dry nitrogen. As expected, decomposition onset temperature of the matrix was shifted compared to standard thermoplastic polymers [31, 32] since PEEK was a heat-resistant polymer. The maximum decomposition rate recorded for the matrix tested alone was $48 \%$, the residual mass being commonly established as a solid carbonaceous char [33]. Virgin carbon fibers, as single fibers directly in contact with the hot $\mathrm{N}_{2}$ atmosphere, were degraded in the range of $640{ }^{\circ} \mathrm{C}$ to $1000{ }^{\circ} \mathrm{C}$, with a total mass loss of $26 \%$. This experiment indicated that the surface of carbon fibers should reach at least $640{ }^{\circ} \mathrm{C}$ to start its thermal decomposition. The thermal degradation of the composite was limited, with a total mass loss of $20 \%$ in the range of $515{ }^{\circ} \mathrm{C}$ to
$1000{ }^{\circ} \mathrm{C}$. Since the PEEK polymer represented $42 \mathrm{wt} . \%$ of the composite, the matrix decomposition should correspond to $19 \%$ mass loss. This was close to the experimental value of $20 \%$, meaning that a weak mass loss can be attributed to the degradation of carbon fibers.

Indeed, as illustrated in Fig. 3, the composite shows two distinct regions of degradation, with a mass loss observed between $640{ }^{\circ} \mathrm{C}$ and $1000{ }^{\circ} \mathrm{C}$ of only 3 wt. $\%$. Nevertheless, the comparison of the three TG curves suggested that the carbon fibers into the composite were not clearly degraded. This was deduced since the fiber surfaces were not in direct contact with the atmosphere, protected by a non-porous film of PEEK char. Therefore, the thermal degradation in dry nitrogen resulted in a partial degradation of the polymer matrix and almost preserved the carbon fibers. When adding steam, the decomposition onset temperature shifted to $530{ }^{\circ} \mathrm{C}$ and the total mass loss reached $21 \mathrm{wt}$.\%. In addition, the maximum reaction peak also shifted to $575{ }^{\circ} \mathrm{C}$ in the presence of steam (against $555^{\circ} \mathrm{C}$ in dry nitrogen). However, in both cases, the degradation process seemed to be achieved around $800{ }^{\circ} \mathrm{C}$. The presence of steam in the atmosphere had no significant effect on the matrix degradation since similar total mass loss was observed for dry and wet nitrogen.

Turning to air, as showed in Fig. 4a, the degradation of the virgin carbon fiber, composite and matrix started at $510{ }^{\circ} \mathrm{C}$. The oxidation of each sample was fully achieved, meaning that the overall composite (matrix and carbon fibers), was entirely oxidized in these conditions. With the presence of steam, the decomposition onset temperature was $530{ }^{\circ} \mathrm{C}$ and a temperature shift was observed for both reaction peaks, while the end of the degradation occurred at $820^{\circ} \mathrm{C}$ (against $880{ }^{\circ} \mathrm{C}$ in dry air). Therefore, steam seemed to globally act as a thermal retardant for the two first degradation steps and as a "catalyst" for the fiber oxidation.

DTG curves, Figs. $3 \mathrm{~b}$ and 4b, enabled the identification of degradation mechanisms of PEEK and carbon fibers according to the atmosphere. In nitrogen and air, a composite mass loss was observed from $510{ }^{\circ} \mathrm{C}$ to $580{ }^{\circ} \mathrm{C}$, corresponding to approximately $15 \mathrm{wt} . \%$ of the initial mass. This first stage was similar in both atmospheres, meaning that only
Table 2 Comparison of thermal stability parameters from TGA analysis

\begin{tabular}{lllll}
\hline Sample & Atmosphere & $\begin{array}{l}\text { Decomposition onset } \\
\text { temperature }\left({ }^{\circ} \mathrm{C}\right)\end{array}$ & $\begin{array}{l}\text { Temperature at mass loss } \\
\text { stabilization }\left({ }^{\circ} \mathrm{C}\right)\end{array}$ & Weight loss $(\%)$ \\
\hline CPEEK & $\mathrm{N}_{2}$ & 515 & 820 & 20 \\
CPEEK & $\mathrm{N}_{2}+$ steam & 530 & 780 & 21 \\
CPEEK & Air & 510 & 880 & 100 \\
CPEEK & Air + steam & 530 & 820 & 100 \\
PEEK & $\mathrm{N}_{2}$ & 515 & 820 & 48 \\
PEEK & Air & 500 & 700 & 100 \\
FT300 & $\mathrm{N}_{2}$ & 640 & $(-)$ & 26 \\
FT300 & Air & 515 & 750 & 100 \\
\hline
\end{tabular}


Fig. 3 TGA curves a and DTG curves $\mathbf{b}$ of PEEK matrix, PEEK composite and FT300 carbon fiber under nitrogen atmospheres at $5{ }^{\circ} \mathrm{C} / \mathrm{min}$ heating rate
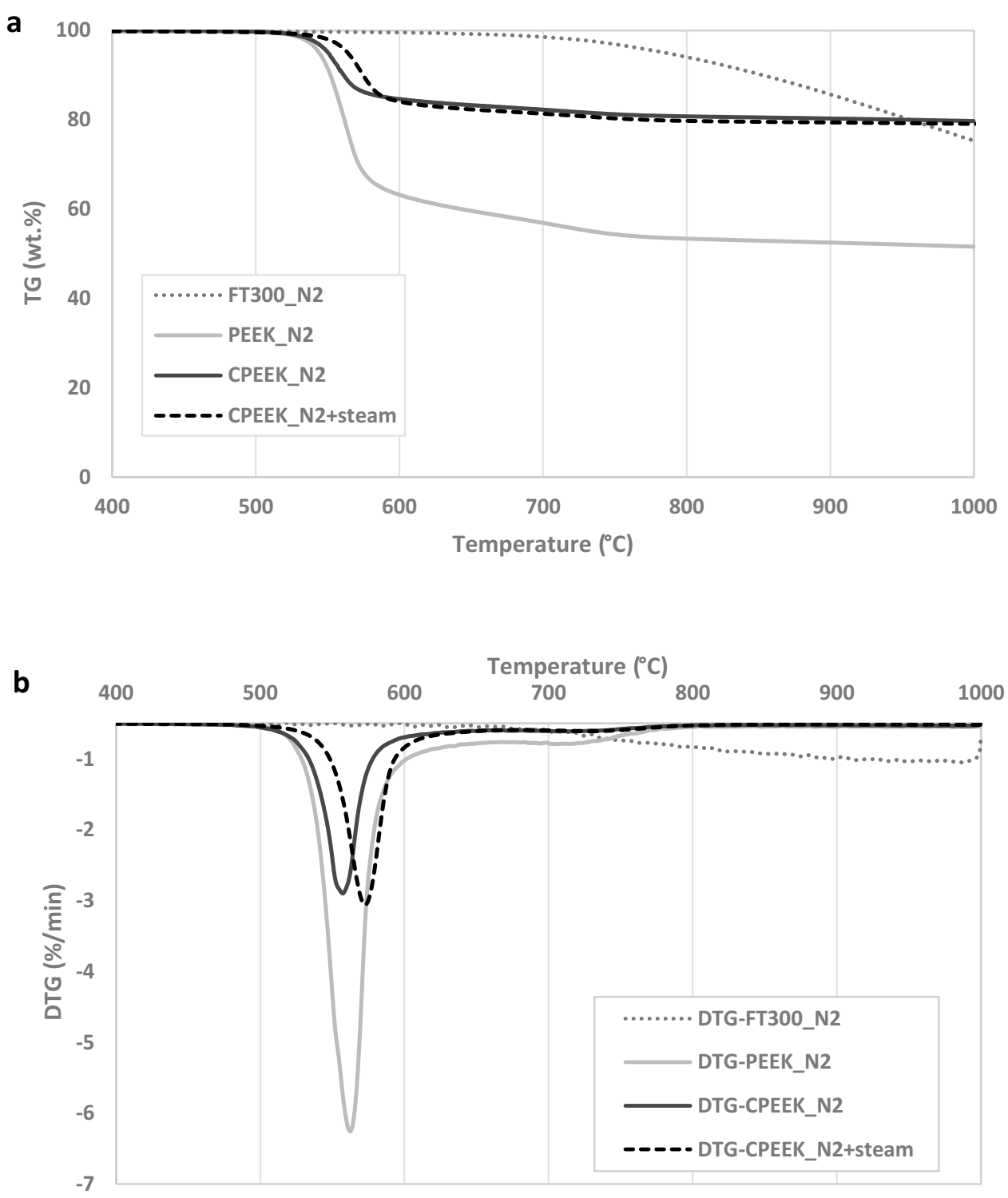

the thermal action initiated the degradation. This step was attributed to random hemolytic scission of either the ether or the carbonyl bonds in the polymer chain [33]. After $580{ }^{\circ} \mathrm{C}$, the degradation behavior split according to the atmosphere.

In nitrogen atmosphere, a slight decrease in the composite mass loss was observed from $580{ }^{\circ} \mathrm{C}$ to $800{ }^{\circ} \mathrm{C}$ ending in a stabilization at only $20 \%$ of the initial mass (Fig. $3 \mathrm{a}$ ). This second reaction resulted in volatilization of the residues formed during the first stage of decomposition [34]. The significant mass loss of virgin carbon fiber reflected the volatilization of heteroatoms present in the precursors of the fiber [35]. In air atmosphere, the composite mass loss was amplified after $580{ }^{\circ} \mathrm{C}$ until $880{ }^{\circ} \mathrm{C}$ where the full oxidation of the entire material was achieved. Derivative curves (Fig. 4b) for PEEK composite and PEEK matrix showed respectively three and two reaction peaks between $500{ }^{\circ} \mathrm{C}$ and $880{ }^{\circ} \mathrm{C}$.

The first DTG peak $\left(500-580{ }^{\circ} \mathrm{C}\right)$, detailed before, was almost similar between the PEEK matrix and the composite. Right after, the second DTG peak $\left(580-680{ }^{\circ} \mathrm{C}\right)$ was identified as the oxidation of the PEEK char formed during the first step, in the matrix and in the composite as well. The mass loss at $680{ }^{\circ} \mathrm{C}$ was $98 \%$ for the PEEK matrix and was $48 \%$ for the composite (representing more than the matrix rate of $42 \mathrm{wt} . \%$ ). While the composite demonstrated a 3rd DTG peak starting from $680{ }^{\circ} \mathrm{C}$, the full oxidation was achieved at $690{ }^{\circ} \mathrm{C}$ in the matrix tested alone. Therefore, the superimposition of PEEK polymer and carbon fiber oxidations was limited. These DTG profiles also indicated that the carbon fiber oxidation started as soon as the surface 
Fig. 4 TGA curves a and DTG curves $\mathbf{b}$ of PEEK matrix, PEEK composite and FT300 carbon fiber under air atmospheres at $5{ }^{\circ} \mathrm{C} / \mathrm{min}$ heating rate
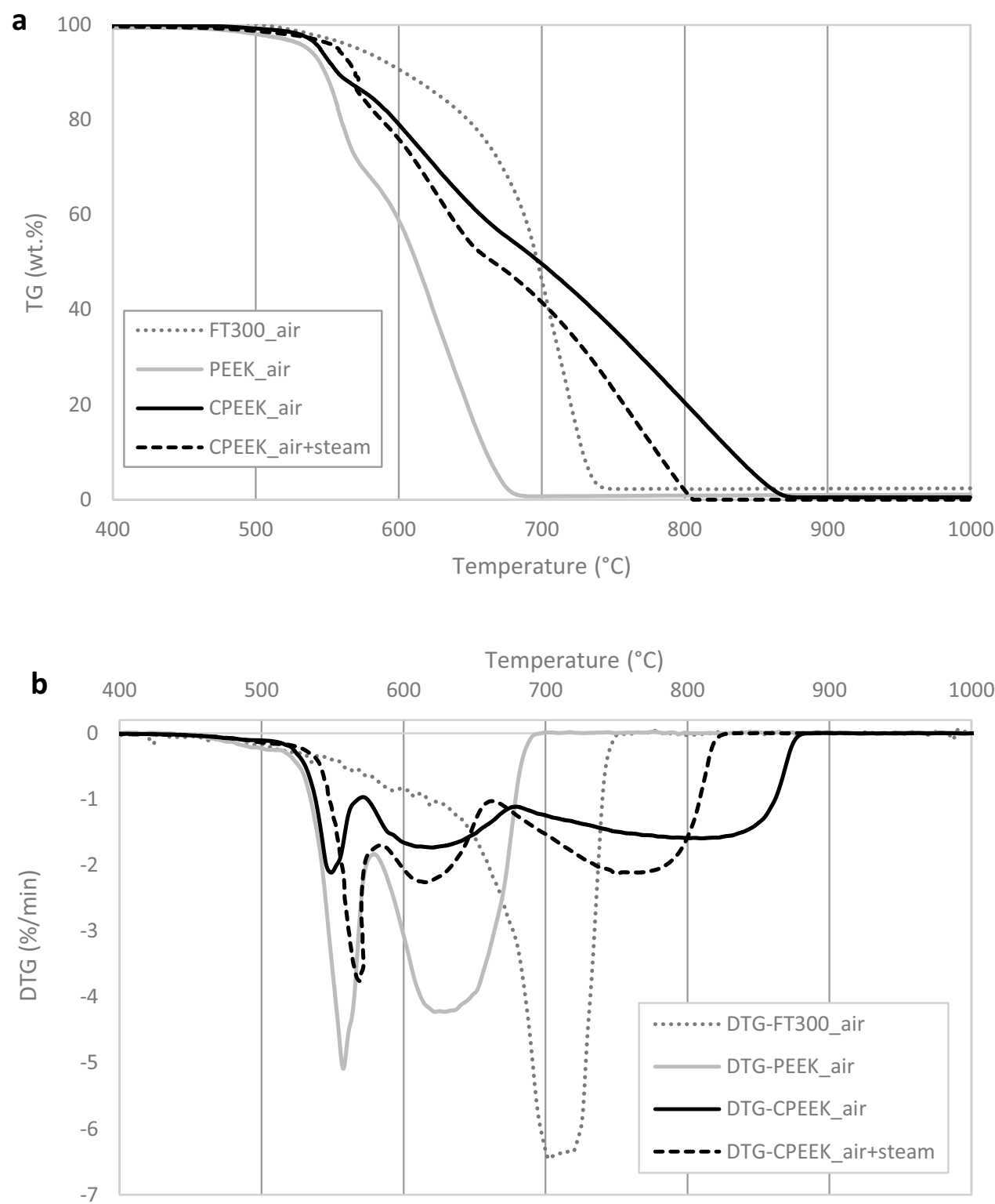

was exposed to air atmosphere as the polymer was fully degraded.

In all atmosphere conditions, the presence of carbon fibers into the PEEK matrix seemed to impact the degradation kinetics in comparison to the matrix alone. This phenomenon was already observed in the literature and was a consequence of the high thermal conductivity of the carbon fibers [36-38]. Furthermore, the comparison of air and nitrogen thermograms with and without humidity highlighted some differences on the composite thermal response. As shown in Table 2, the presence of humidity appeared to increase the decomposition onset temperature for both gases. In wet nitrogen, a small increase of final mass was observed. For air conditions, as shown in Fig. 4b, the total decomposition of the composite was faster with the presence of steam. This slight change in degradation behavior remained negligible in dynamic thermogravimetry, nonetheless it was expected to be more pronounced in isothermal operating conditions. The matrix decomposition reactions under nitrogen and air (with and without humidity) had been reported as exothermic reactions, which will impact the local temperature of larger samples used at pilot scale. These thermogravimetric analyses were used as a support for comparison and understanding of the thermochemical mechanisms involved during recycling at the pilot scale.

\section{Matrix Degradation Rate at Pilot Scale}

PEEK composite recycling has been assessed through four inert and oxidative atmospheres: nitrogen $(\mathrm{N})$, nitrogen and 
steam (NS), air (A) and air and steam (AS). A temperature of $550{ }^{\circ} \mathrm{C}$ was selected to perform the experiments to reach the decomposition onset temperature of PEEK matrix highlighted by TGA analysis. The maximum temperature recorded for all tests was around $580{ }^{\circ} \mathrm{C}$, which located the treatment in the first matrix degradation step and prevented fiber degradation induced by higher temperature. The results from pilot scale recycling treatment are shown in Table 3. For each condition, the isothermal average temperature and the maximal temperature were measured. At the end of the treatment the recovered solid was weighed to determine the mass loss percentage and the matrix degradation rate.

Table 3 shows that the total mass loss in nitrogen and nitrogen/steam atmospheres reached $18 \mathrm{wt} . \%$ and $21 \mathrm{wt} . \%$ respectively, while in air and air/steam atmosphere, it reached $50 \mathrm{wt} . \%$ and $48 \mathrm{wt} . \%$ respectively. These results are in fair agreement with the preliminary TGA analysis conducted at micro scale. Since the objective was to remove the matrix and preserve the carbon fibers, the matrix conversion was compared in each condition. In nitrogen and nitrogen/ steam atmosphere the matrix conversion was lower (42 wt.\% and $46 \mathrm{wt} . \%$ respectively) compared to air and air/steam atmospheres. Matrix conversion in nitrogen conditions was not satisfactory to allow the extraction of rCF. The recovered solids were still containing a large amount of carbonaceous material. As illustrated in Fig. 5(b), the important quantity of char after treatment proved that the carbonization (first degradation reaction) occurred. This char may still contain typical PEEK structural parts like ketone groups and aromatics ether linkage depending on the atmosphere and degradation mechanisms [39]. The presence of steam had a small impact on the global decomposition in nitrogen, while this atmosphere significantly improved the degradation of thermosetting and standard thermoplastic matrix [20].

A significant increase in the matrix removal was found in oxidative atmosphere, reaching $119 \%$ and $112 \%$ in air and air/steam respectively, indicating a partial degradation of the carbon fibers. Based on Table 2, the decomposition onset temperature of carbon fiber was estimated at $515^{\circ} \mathrm{C}$ in air when the fiber was fully in contact with the surrounding atmosphere. Therefore, with the reaction temperature and the duration time selected, the oxidation of carbon fibers was expected to start once the fibers were in direct contact with the atmosphere.

Finally, the fiber exposition to the atmosphere was progressive and dependent to the heterogeneity in matrix decomposition along the reaction time. This also means that the oxidation reactions can be performed at a temperature lower than $580{ }^{\circ} \mathrm{C}$. The PEEK exothermic reactions may raise the temperature, and locally allowed to reach the energy barrier required for oxidation. The trials performed with steam seemed to be less aggressive, maybe because oxidation reactions were partially inhibited by steam flow. The complete elimination of matrix and the extraction of the fibers was only possible for CPEEK-A and CPEEK-AS samples (see Fig. 5c), proving that a certain quantity of oxygen was necessary to reclaim carbon fibers from PEEK composite. But in oxidative treatments the reclaimed carbon fiber was attacked and may suffer from an alteration of its surface aspect and intrinsic mechanical properties. Morphological and mechanical analyses were performed on extractible rCFs from CPEEK-A and CPEEK-AS samples to confirm
Table 3 Process controlled temperatures and sample weight losses at different atmospheres (average results from triplicate)

\begin{tabular}{llllr}
\hline Sample & $\begin{array}{l}\text { Average isotherm tem- } \\
\text { perature }\left({ }^{\circ} \mathrm{C}\right)\end{array}$ & $\begin{array}{l}\text { Average maximum } \\
\text { temperature }\left({ }^{\circ} \mathrm{C}\right)\end{array}$ & $\%$ mass loss $(\%)$ & $y_{m}(\%)$ \\
\hline $\mathrm{C}_{\mathrm{PEEK}}-\mathrm{N}$ & 553 & 582 & $18 \pm 0.6$ & $42 \pm 1.4$ \\
$\mathrm{C}_{\mathrm{PEEK}}-\mathrm{NS}$ & 554 & 580 & $21 \pm 1.3$ & $46 \pm 3.1$ \\
$\mathrm{C}_{\mathrm{PEEK}^{-}}-\mathrm{A}$ & 556 & 589 & $50 \pm 0.4$ & $119 \pm 0.9$ \\
$\mathrm{C}_{\mathrm{PEEK}}-\mathrm{AS}$ & 552 & 582 & $48 \pm 0.8$ & $112 \pm 1.9$ \\
\hline
\end{tabular}
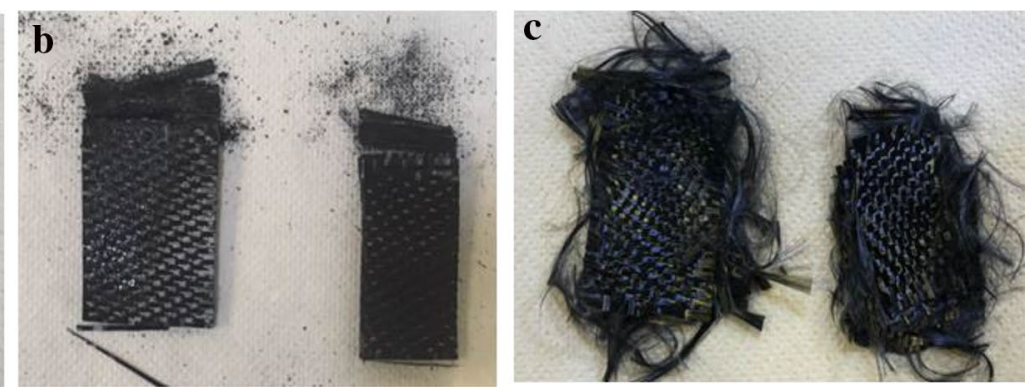

Fig. 5 a PEEK composites before recycling, $\mathbf{b}$ recovered solid from thermal treatment under nitrogen and $\mathbf{c}$ air 
this assumption. To limit the variability induced by matrix degradation along the sample thickness, the rCFs characterizations were done in different locations. Morphological and mechanical analyses were interpreted together with the matrix degradation rate.

\section{Morphological Analysis of rCF}

Besides thermogravimetric results, the $\mathrm{rCF}$ surfaces were observed using SEM. As the carbon fibers from nitrogen conditions were not extractable and covered by a matrix char residue (see Fig. 5), only fibers resulting from the air conditions with and without steam were tested. Two rCF sampling areas were defined to be as representative as possible; $z 1$ for external zone, z2 for internal zone. Figure 6 displays the $\mathrm{rCF}$ average aspect for air and air/ steam conditions in comparison with virgin FT300 and unsized FT300 (Fig. 6a). Virgin carbon fiber FT300 showed a ribbed surface induced by the carbon fiber manufacturing process. These ridges were more pronounced for the unsized sample. Recycling carbon fiber for proper reuse should present a clean surface such as unsized carbon fiber.

Reclaimed fibers from air treatment were easily separated from each other in both zones as seen in Fig. 6b. This observation agreed with the total mass loss calculated in the previous section. Surface defects like holes and some residues (matrix char or impurities) were locally observed on recovered carbon fibers. This confirmed the hypothesis of a fiber surface oxidation. Furthermore, striations on rCF surfaces could also be identified along the longitudinal axis. The same observation was made for the unsized virgin FT300. Therefore, the recycling process in oxidative atmosphere seemed to remove the carbon fiber sizing together with the matrix decomposition.

In air and steam condition (Fig. 6c), rCF likely presented a clean surface. Tiny defaults were found in sampling area 1 and residual matrix char in sampling area 2. In that case, the fiber oxidation seemed less aggressive and heterogeneous with the presence of steam, which agreed with the matrix degradation rates calculated above. More generally in both atmosphere conditions, reclaimed fiber surface aspect varied according to the sampling area. The external zones presented more surface degradation marks and the internal zones seemed less degraded. The gas may have some difficulties to reach the core of the composite and a limitation of the diffusion was observed, even more with the presence of steam. An increase of air and steam flow rate may limit this heterogeneity but increase the fiber surface oxidation.

Fiber diameters were calculated by image analysis, the results for each sampling area are presented in Table 4. A significant reduction in rCF diameters, ranging from $6.64 \mu \mathrm{m}$ to $7.05 \mu \mathrm{m}$, was observed compared to that of the virgin fiber $(7.30 \mu \mathrm{m})$. This result exhibited an alteration of carbon fiber surface in accordance with the matrix degradation rates higher than 100\%. Diameters of the external fibers (sampling area 1) were smaller than those of the internal fibers (sampling area 2 . These observations highlighted the heterogeneity of the material degradation and rCFs morphology along the thickness of the composite.

\section{Single Filament Tensile Test}

As mentioned previously, carbon fiber mechanical properties are of utmost importance in their reusability. The results of the tensile strength are presented in Table 5. The original FT300 virgin fibers presented a tensile strength of $3530 \mathrm{MPa}$, and the retention of the tensile strength $\mathrm{R}$ was then calculated. Table 5 shows that the rCF from air and air/ steam treatments had quite good tensile strength of at least $71 \%$ of that of virgin carbon fibers. The difference of results between dry and wet atmosphere could not be directly interpreted. The presence of steam had an influence on the matrix degradation heterogeneity and therefore on morphological aspect of fiber surface and flaw occurrence.

In sampling area 1 , the tensile strength was satisfactory, with a retention of $83 \%$ and $90 \%$ for air and air/steam atmospheres respectively, despite of the diameter reduction caused by the oxidative atmosphere. This would indicate that the degradation of the surface was almost homogeneous and mainly acted like an "exfoliation". However, some differences occured according to the sampling area, especially in air/steam condition. Indeed, the tensile strength decreased from the external to the internal zone, from 3191 to $2498 \mathrm{MPa}$. This decrease in mechanical resistance was probably due to a higher morphological heterogeneity in this zone. According to the SEM images (Fig. 6c), the carbon fibers from the internal zone presented local roughness due to residual matrix char, and a larger average diameter. Surface and volume defects generated stress concentration, responsible of the crack initiation and propagation leading to a premature failure of the fiber [12]. The rCFs were moderately impacted by the treatment since the retention of the mechanical properties from the CPEEK-A and CPEEK-AS samples (all zones) was $85 \%$ and $81 \%$ respectively, which was convenient for a future reuse.

Weibull statistical analysis parameters are presented in Table 5. Recycled carbon fibers exhibited low values of Weibull modulus, from 3.79 to 5.97 , compared to the virgin FT300 $(8,28)$. This observation indicated an increase of surface defects occurrence and their criticality. As previously mentioned, major changes were revealed on the rCFs surface morphology, which directly impacted the uniformity of the Weibull defects distribution.

The majority of rCFs characterized presented a scale parameter higher than the reference value (3012 MPa), from 3243 to $3542 \mathrm{MPa}$. The number of filaments supporting 


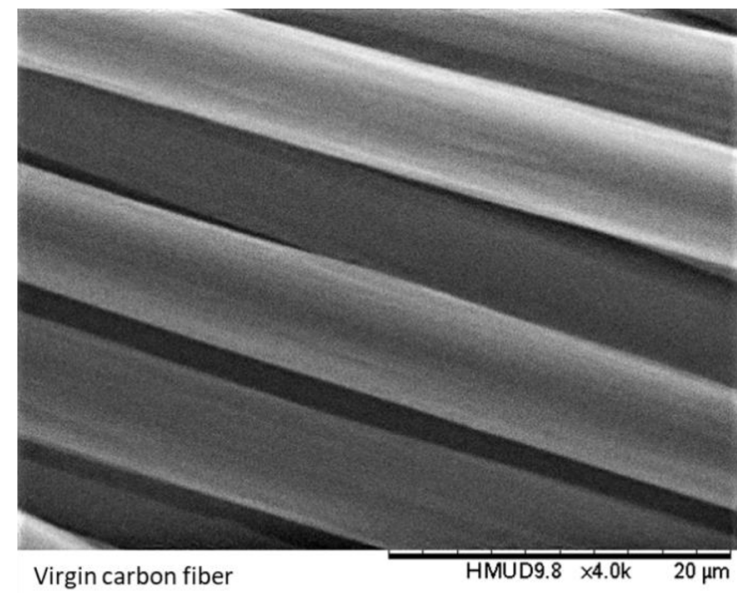

Virgin carbon fiber FT300

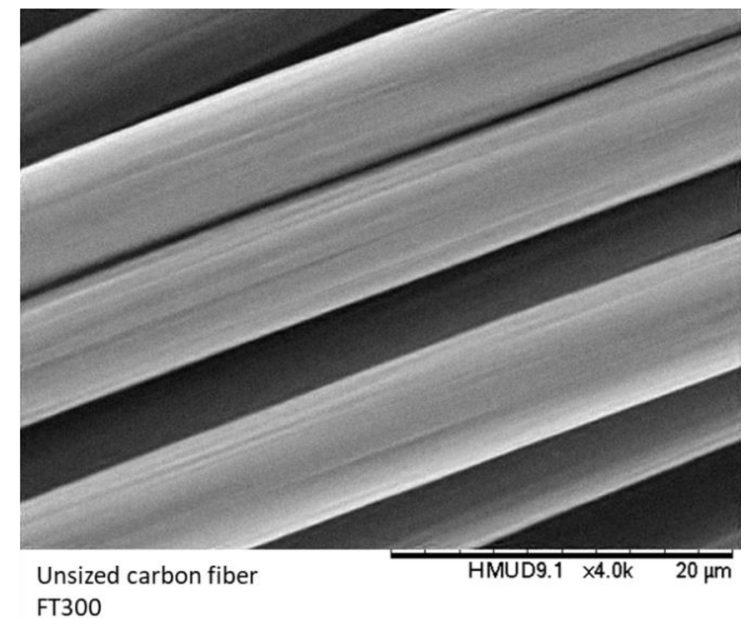

FT300

a Reference carbon fiber virgin and chemically unsized FT300

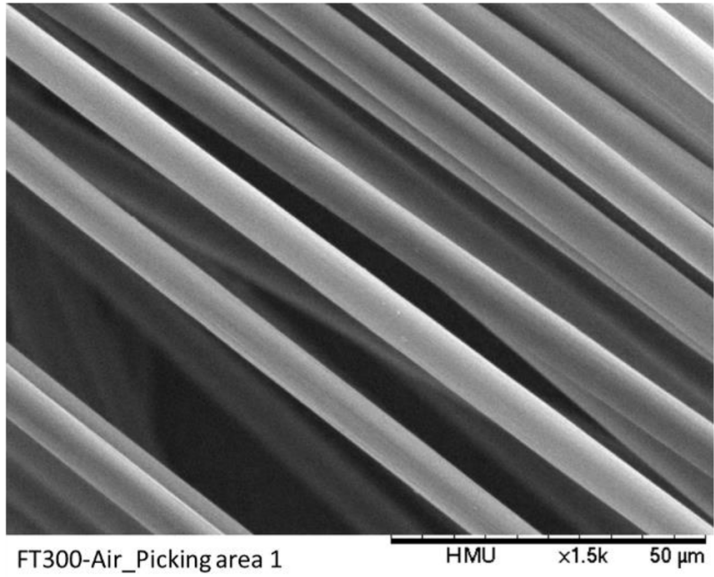

average

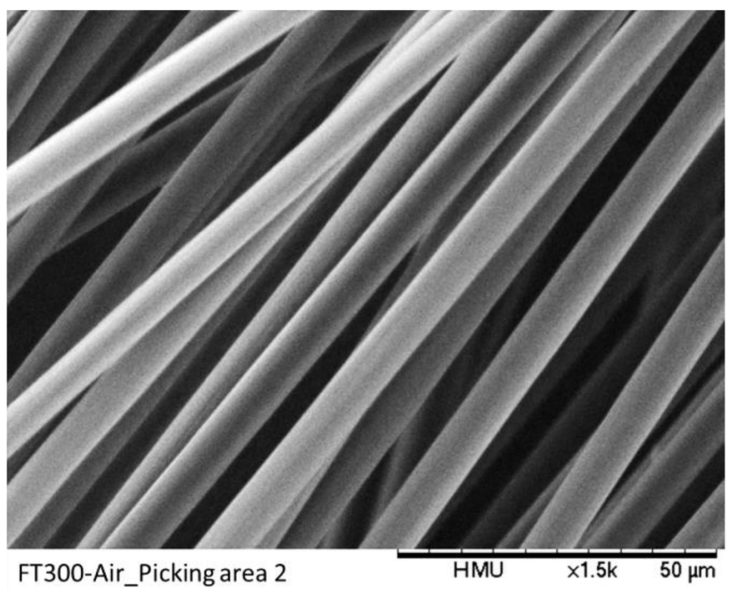

average

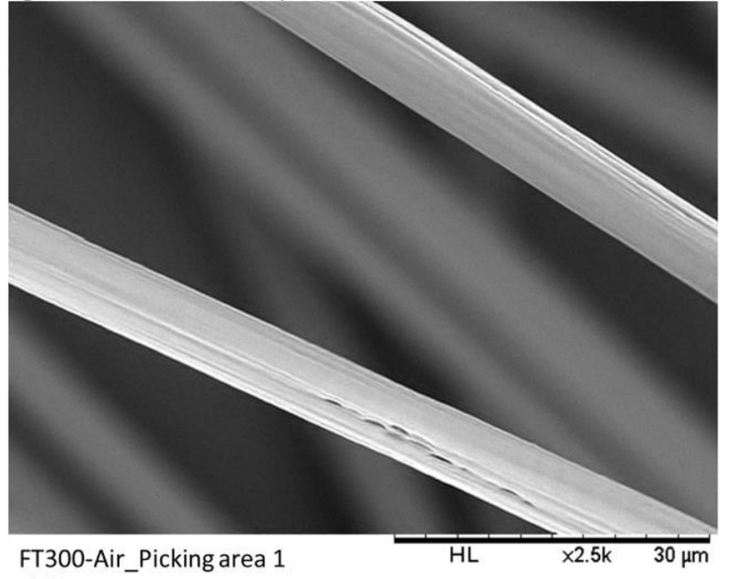

defect zone

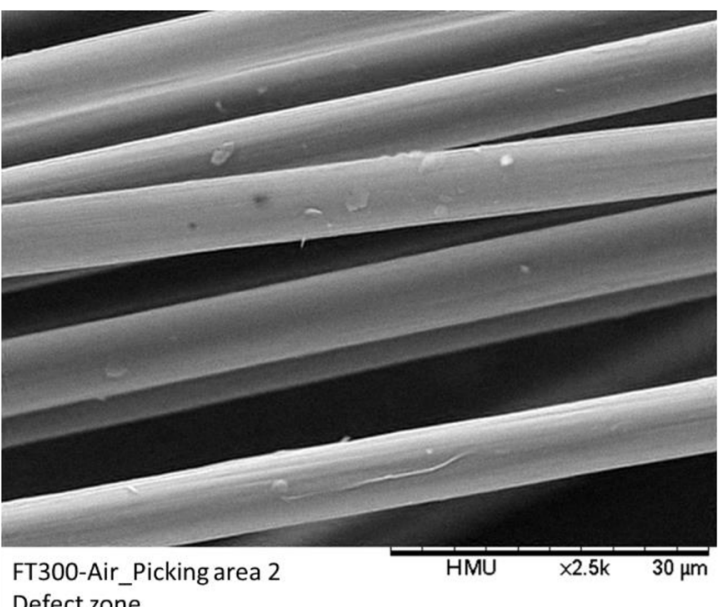

Defect zone

\section{b Reclaimed fiber from air condition}

Fig. 6 SEM micrographs of virgin and reclaimed FT300 carbon fiber from oxidative treatments

high stresses was increased, but as regards to their Weibull modulus, fibers broke at lower stresses than usual. The sample CPEEK-AS (zone 2) showed an important decrease of the scale parameter compared to other samples, due to the matrix degradation heterogeneity. Finally, the values of the calculated Weibull parameters were consistent with the 


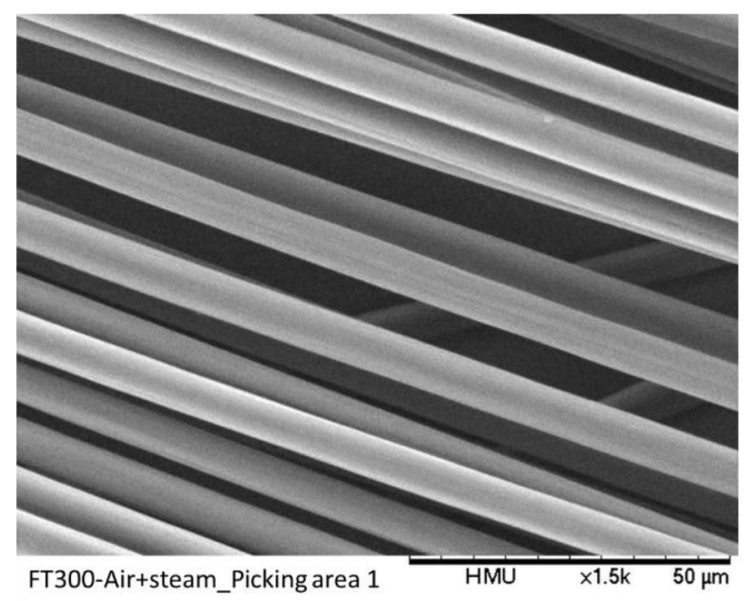

average

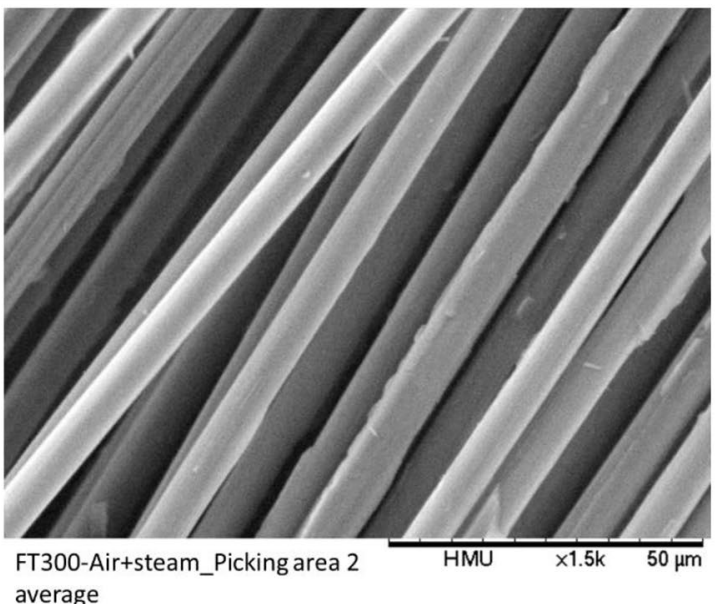

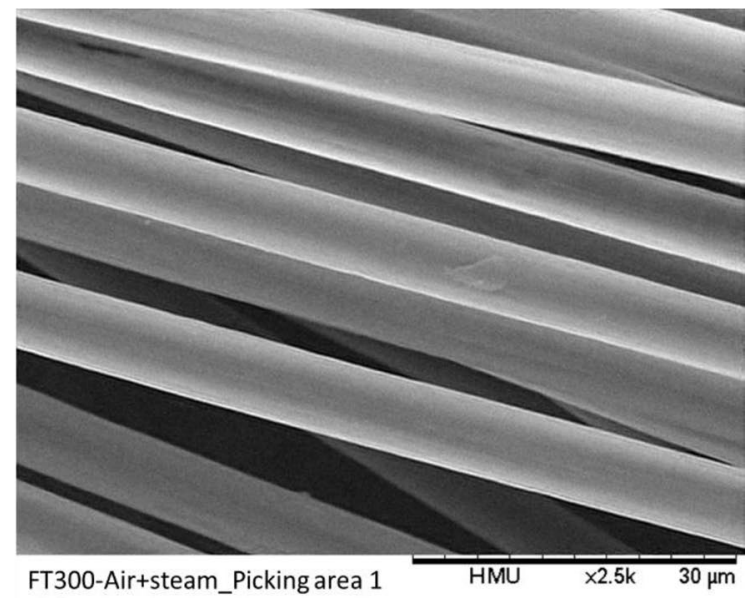

defect zone

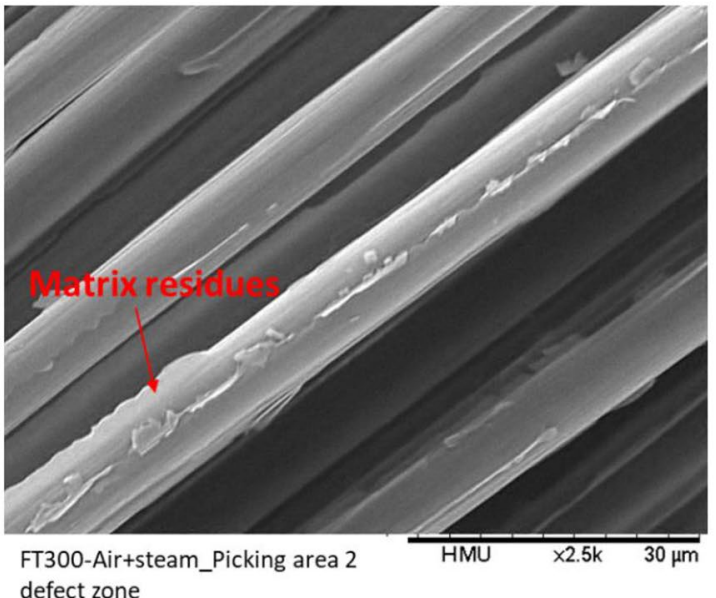

defect zone

\section{c Reclaimed carbon fiber from air with steam condition}

Fig. 6 (continued)

Table 4 Reported fibers diameters from air conditions

\begin{tabular}{lllll}
\hline Sample & Zone 1 $(\mu \mathrm{m})$ & Zone 2 $(\mu \mathrm{m})$ & Average $(\mu \mathrm{m})$ & $y_{m}(\%)$ \\
\hline CPEEK-A & $6.64 \pm 0.37$ & $7.05 \pm 0.24$ & $6.84 \pm 0.37$ & $119 \pm 0.9$ \\
CPEEK-AS & $6.75 \pm 0.26$ & $7.04 \pm 0.34$ & $6.91 \pm 0.33$ & $112 \pm 1.9$ \\
\hline
\end{tabular}

variation of the breaking stresses and the measured standard deviations. Even if good retention of the mechanical properties was found, the recycling process seemed to significantly change the surface defects probability, which need to be taken into account for future reuse.

\section{Discussion}

Experimental results of TGA analysis, matrix degradation rate at pilot scale, and post-treatment characterizations of the carbon fibers have led to these observations:
Table 5 Mechanical properties of reclaimed $\mathrm{rCF}$ under air conditions

\begin{tabular}{|c|c|c|c|c|}
\hline \multirow{2}{*}{$\begin{array}{l}\text { Sample } \\
\text { Zone }\end{array}$} & \multicolumn{2}{|l|}{ CPEEK-A } & \multicolumn{2}{|l|}{ CPEEK-AS } \\
\hline & 1 & 2 & 1 & 2 \\
\hline$\sigma(\mathrm{MPa})$ & $2942 \pm 501$ & $3072 \pm 665$ & $3191 \pm 560$ & $2498 \pm 528$ \\
\hline $\mathrm{R}$ & $83 \%$ & $87 \%$ & $90 \%$ & $71 \%$ \\
\hline Weibull modulus $m$ & 5.97 & 5.02 & 5.15 & 3.79 \\
\hline Scale parameter $\sigma_{0}(\mathrm{MPa})$ & 3243 & 3426 & 3542 & 2894 \\
\hline
\end{tabular}


- Trials campaigns carried on under nitrogen (with and without humidity) did not provide optimum atmosphere to reach a matrix degradation rate up to $75 \%$ for extraction, characterization, and valorization of carbon fiber from PEEK composites. This behavior was directly linked to the heat-resistant character of the polymeric matrix.

- In air atmosphere, the PEEK matrix decomposition can be achieved, but the atmosphere also caused oxidation of carbon fibers surface and a reduction of their mechanical properties. At pilot scale, heterogeneous physicochemical properties of $\mathrm{rCF}$ were observed between core and external zones. Fibers located in the external zone were in direct contact with the atmosphere, and the oxidation occurred to a larger extent.

- Steam tended to disrupt the heat transfers. It can be observed at pilot scale, where an improvement on the matrix degradation rate in wet nitrogen was observed. Moreover, in air atmosphere, steam was beneficial to protect the surface of fibers in direct contact with the surrounding gas, while it limited the degradation in the core zones.

- Morphological and mechanical properties of recycled carbon fibers were interdependent and sensitive to matrix degradation heterogeneity.

These tests clearly highlighted the issues in recycling composites with a heat-resistant matrix. Traditional methods used in our previous studies, such as pyrolysis and steamthermolysis $[18,20]$ were not efficient to provide a separation of the two components. As expected, oxygen was efficient to break the linkage between the matrix and the fiber, but the operating parameters should be optimized to avoid any rCF surface degradation. Steam had a certain influence on the composite degradation behavior and so on the recovered solid. Further investigations on the kinetics mechanisms under steam-thermolysis should be performed in order to clarify the steam impact on chain breakages. Results presented so far in this paper only give a first insight on the thermochemical recycling of PEEK/carbon composite at micro scale and semi-industrial scale. It should be noted that pilot scale treatments were done with few amounts of PEEK composite $(20 \mathrm{~g})$. More mass should be used to highlight any scale effect. However, the presence of continuous air into the reactor may lead to the combustion of the material. This issue needs to be considered for bigger scale recycling tests.

\section{Conclusion}

The results presented in this work provided insights and comparisons about PEEK / carbon compound thermochemical recycling on a micro and semi-industrial scale.
At micro scale, PEEK composite presented a negligible thermal decomposition below $510{ }^{\circ} \mathrm{C}$ in inert and oxidative atmosphere. The total decomposition of the matrix was only possible in air conditions, which led necessarily to the degradation of carbon fiber. Isothermal treatments of PEEK composite at pilot scale were then carried out at $580{ }^{\circ} \mathrm{C}$, and resulted in the same observations on the material degradation behaviors. Morphological analysis of the recovered carbon fiber from air conditions highlighted the impact of the recycling treatment on the fiber. Single tensile tests revealed that these carbon fibers are still reusable with an average retention of mechanical properties of $81-85 \%$ in oxidative treatments. For future rCFs reuse, important consideration should be done to the increase of surface defects. Feasibility of PEEK composite recycling treatment at moderate temperature $\left(500-600{ }^{\circ} \mathrm{C}\right)$ was satisfactory, but the presence of continuous air implies safety risks. Consequently, future studies should be made on oxidative post treatment or mixed atmosphere treatment. As improvement route, optimization of air and steam flow rate could be carried out to reduce matrix decomposition heterogeneity along the composite thickness. The quantification of oxygen content on carbon fiber surface may help to better understand the impact of operating conditions.

Acknowledgement Financial support by IMT Mines Albi, ADEME (Agence de l'environnement et de la maîtrise de l'énergie) and FAPESP (Processo:16/19896-2 Linha de fomento: Auxílio à Pesquisa Regular). RAPSODEE laboratory for technical support.

\section{References}

1. Mallick, P.K.: Fiber-reinforced composites materials, manufacturing, and design. CRC, Boca Raton (2008)

2. Koumoulos, E.P., et al.: Research and development in carbon fibers and advanced high-performance composites supply chain in europe: a roadmap for challenges and the industrial uptake. J. Compos. Sci. 3(3), 86 (2019). https://doi.org/10.3390/jcs3030086

3. Holmes, M.: Global carbon fibre market remains on upward trend. Reinf. Plast. 58(6), 38-45 (2014). https://doi.org/10.1016/S00343617(14)70251-6

4. Post, W., Susa, A., Blaauw, R., Molenveld, K., Knoop, R.J.I.: A Review on the potential and limitations of recyclable thermosets for structural applications. Polym. Rev. 60(2), 359-388 (2020). https://doi.org/10.1080/15583724.2019.1673406

5. Sudhin, A., Remanan, M., Ajeesh, G., Jayanarayanan, K.: Comparison of properties of carbon fiber reinforced thermoplastic and thermosetting composites for aerospace applications. Materials Today: Proceedings 24, 453-462 (2020). https://doi.org/10.1016/j. matpr.2020.04.297

6. Muzzy, J.D., Kays, A.O.: Thermoplastic vs. thermosetting structural composites. Polym. Compos. 5(3), 169-172 (1984). https:// doi.org/10.1002/pc.750050302

7. Vieille, B., Albouy, W., Chevalier, L., Taleb, L.: About the influence of stamping on thermoplastic-based composites for aeronautical applications. Compos. B Eng. 45(1), 821-834 (2013). https:// doi.org/10.1016/j.compositesb.2012.07.047 
8. Biron, M.: Thermoplastics and thermoplastic composites: technical information for plastics users. Elsevier, BH, Amsterdam (2006)

9. Naqvi, S.R., Prabhakara, H.M., Bramer, E.A., Dierkes, W., Akkerman, R., Brem, G.: A critical review on recycling of end-of-life carbon fibre/glass fibre reinforced composites waste using pyrolysis towards a circular economy. Resour. Conserv. Recycl. 136, 118-129 (2018). https://doi.org/10.1016/j.resconrec.2018.04.013

10. Giorgini, L., Benelli, T., Brancolini, G., Mazzocchetti, L.: Recycling of carbon fiber reinforced composite waste to close their life cycle in a cradle-to-cradle approach. Current Opinion in Green and Sustainable Chemistry 26, 100368 (2020). https://doi.org/10. 1016/j.cogsc. 2020.100368

11. Hagnell, M.K., Åkermo, M.: The economic and mechanical potential of closed loop material usage and recycling of fibre-reinforced composite materials. J. Clean. Prod. 223, 957-968 (2019). https:// doi.org/10.1016/j.jclepro.2019.03.156

12. Zhang, J., Chevali, V.S., Wang, H., Wang, C.-H.: Current status of carbon fibre and carbon fibre composites recycling. Compos. B Eng. 193, 108053 (2020). https://doi.org/10.1016/j.compositesb. 2020.108053

13. Meng, F., McKechnie, J., Pickering, S.J.: An assessment of financial viability of recycled carbon fibre in automotive applications. Compos. A Appl. Sci. Manuf. 109, 207-220 (2018). https://doi. org/10.1016/j.compositesa.2018.03.011

14. G. Oliveux, L. O. Dandy, and G. A. Leeke, "Current status of recycling of fibre reinforced polymers: Review of technologies, reuse and resulting properties," Progress in Materials Science, $\mathrm{p}$. 39, 2015

15. A. Fernández, C. S. Lopes, C. González, and F. A. López, "Characterization of Carbon Fibers Recovered by Pyrolysis of Cured Prepregs and Their Reuse in New Composites," in Recent Developments in the Field of Carbon Fibers, R. Khanna and R. Cayumil, Eds. InTech, 2018.

16. Meyer, L.O., Schulte, K., Grove-Nielsen, E.: CFRP-recycling following a pyrolysis route: process optimization and potentials. J. Compos. Mater. 43(9), 1121-1132 (2009). https://doi.org/10. $1177 / 0021998308097737$

17. Jiang, G., Pickering, S.J.: Structure-property relationship of recycled carbon fibres revealed by pyrolysis recycling process. J Mater Sci 51(4), 1949-1958 (2016). https://doi.org/10.1007/ s10853-015-9502-2

18. Ye, S.Y., Bounaceur, A., Soudais, Y., Barna, R.: Parameter optimization of the steam thermolysis: a process to recover carbon fibers from polymer-matrix composites. Waste Biomass Valor 4(1), 73-86 (2013). https://doi.org/10.1007/s12649-013-9220-4

19. S. Y. Ye, "Valorisation de déchets composites à matrices polymériques renforcées de fibres de carbone par un procédé de vapo-thermolyse," $\mathrm{PhD}$ Thesis, Institut National Polytechnique de Toulouse, 2012.

20. A. Oliveira Nunes, "Composites renforcés à fibres de carbone : récupération des fibres par vapo-thermolyse, optimisation du procédé," PhD Thesis, Ecole des Mines d'Albi-Carmaux, 2015.

21. Buggy, M., Farragher, L., Madden, W.: Recycling of composite materials. J. Mater. Process. Technol. 55(3-4), 448-456 (1995). https://doi.org/10.1016/0924-0136(95)02037-3

22. Dandy, L.O., Oliveux, G., Wood, J., Jenkins, M.J., Leeke, G.A.: Accelerated degradation of Polyetheretherketone (PEEK) composite materials for recycling applications. Polym. Degrad. Stab. 112, 52-62 (2015). https://doi.org/10.1016/j.polymdegradstab.2014.12. 012

23. Ramakrishna, S., Tan, W.K., Teoh, S.H., Lai, M.O.: Recycling of Carbon Fiber/Peek Composites. KEM 137, 1-8 (1997)

24. M. Roux, C. Dransfeld, N. Eguémann, and L. Giger, "Processing and recycling of thermoplastic composite fibre/PEEK aerospace part," presented at the 16th European Conference on Composite Materials, ECCM 2014, Jan. 2014
25. "EN 2564:2018 - Aerospace series - Carbon fibre laminates Determination of the fibre, resin and void contents." Accessed: Mar. 02, 2021. [Online]. Available: https://standards.iteh.ai/ catalog/standards/cen/2f690182-64ff-47f0-bc85-e90b994165c7/ en-2564-2018.

26. M. Boulanghien, "Formulations de composites thermoplastiques à partir de fibres de carbone recyclées par vapo-thermolyse," $\mathrm{PhD}$ Thesis, Ecole des Mines d'Albi-Carmaux, 2014.

27. Yao, J., Yu, W., Pan, D.: Tensile strength and its variation of PANbased carbon fibers. III. Weak-link analysis. J. Appl. Polym. Sci. 110(6), 3778-3784 (2008). https://doi.org/10.1002/app.24879

28. F. Islam, S. Joannès, L. Laiarinandrasana, and A. Bunsell, "Adaptation of Weibull analysis to represent strength behaviour of brittle fibres," Aug. 2019.

29. Yu, W., Yao, J.: Tensile strength and its variation of PAN-based carbon fibers. I. Statistical distribution and volume dependence. Journal of Applied Polymer Science - J APPL POLYM SCI 101, 3175-3182 (2006). https://doi.org/10.1002/app.23399

30. Harikrishnan, R., Mohite, P.M., Upadhyay, C.S.: Generalized Weibull model-based statistical tensile strength of carbon fibres. Arch Appl Mech 88(9), 1617-1636 (2018). https://doi.org/10. 1007/s00419-018-1391-9

31. Kiran, N., Ekinci, E., Snape, C.E.: Recyling of plastic wastes via pyrolysis. Resour. Conserv. Recycl. 29(4), 273-283 (2000). https://doi.org/10.1016/S0921-3449(00)00052-5

32. S. V. Levchik, E. D. Weil, and M. Lewin, "Thermal decomposition of aliphatic nylons," Polymer International, vol. 48, no. 7, pp. 532-557, Jul. 1999, Accessed: Mar. 02, 2021. [Online]. Available: https://onlinelibrary.wiley.com/doi/abs/https://doi.org/10.1002/\% 28SICI\%291097-0126\%28199907\%2948\%3A7\%3C532\%3A\% 3AAID-PI214\%3E3.0.CO\%3B2-R.

33. Hay, J.N., Kemmish, D.J.: Thermal decomposition of poly(aryl ether ketones). Polymer 28(12), 2047-2051 (1987). https://doi. org/10.1016/0032-3861(87)90039-5

34. Patel, P., Hull, T.R., McCabe, R.W., Flath, D., Grasmeder, J., Percy, M.: Mechanism of thermal decomposition of poly(ether ether ketone) (PEEK) from a review of decomposition studies. Polym. Degrad. Stab. 95(5), 709-718 (2010). https://doi.org/10. 1016/j.polymdegradstab.2010.01.024

35. Wang, S., Chen, Z.-H., Ma, W.-J., Ma, Q.-S.: Influence of heat treatment on physical-chemical properties of PAN-based carbon fiber. Ceram. Int. 32(3), 291-295 (2006). https://doi.org/10.1016/j. ceramint.2005.02.014

36. Patel, P., et al.: Investigation of the thermal decomposition and flammability of PEEK and its carbon and glass-fibre composites. Polym. Degrad. Stab. 96(1), 12-22 (2011). https://doi.org/10. 1016/j.polymdegradstab.2010.11.009

37. Kenny, J.M., Torre, L.: Degradation Kinetics of High-Performance Polymers and Their Composites. High-Temperature Properties and Applications of Polymeric Materials 603, 140-154 (1995)

38. Yao, F., Zheng, J., Qi, M., Wang, W., Qi, Z.: The thermal decomposition kinetics of poly(ether-ether-ketone) (PEEK) and its carbon fiber composite. Thermochim. Acta 183, 91-97 (1991). https://doi.org/10.1016/0040-6031(91)80448-R

39. Hamciuc, C., Lisa, G., Hamciuc, E., Epure, E.-L., Tudorachi, N.: Thermal behavior study and degradation mechanism by TG/MS/ FTIR technique of some poly(aryl ether ether ketone)s. J. Anal. Appl. Pyrol. 150, 104877 (2020). https://doi.org/10.1016/j.jaap. 2020.104877 